\title{
Appropriate Depth of Needle Insertion During Rhomboid Major Trigger Point Block
}

\author{
Seung Jun Seol, MD' ${ }^{1}$, Hyungpil Cho, MD , Do Hyun Yoon, $\mathrm{MD}^{1}$, Seong Ho Jang, $\mathrm{MD}^{2}$ \\ ${ }^{1}$ Department of Rehabilitation Medicine, Hanyang University College of Medicine, Seoul; ${ }^{2}$ Department of \\ Rehabilitation Medicine, Hanyang University Guri Hospital, Hanyang University College of Medicine, Guri, Korea
}

\begin{abstract}
Objective To investigate an appropriate depth of needle insertion during trigger point injection into the rhomboid major muscle.

Methods Sixty-two patients who visited our department with shoulder or upper back pain participated in this study. The distance between the skin and the rhomboid major muscle (SM) and the distance between the skin and rib (SB) were measured using ultrasonography. The subjects were divided into 3 groups according to BMI: BMI less than $23 \mathrm{~kg} / \mathrm{m}^{2}$ (underweight or normal group); $23 \mathrm{~kg} / \mathrm{m}^{2}$ or more to less than $25 \mathrm{~kg} / \mathrm{m}^{2}$ (overweight group); and $25 \mathrm{~kg} / \mathrm{m}^{2}$ or more (obese group). The mean \pm standard deviation (SD) of SM and SB of each group were calculated. A range between mean +1 SD of SM and the mean-1 SD of SB was defined as a safe margin.

Results The underweight or normal group's SM, SB, and the safe margin were $1.2 \pm 0.2,2.1 \pm 0.4$, and 1.4 to $1.7 \mathrm{~cm}$, respectively. The overweight group's SM and SB were $1.4 \pm 0.2$ and $2.4 \pm 0.9 \mathrm{~cm}$, respectively. The safe margin could not be calculated for this group. The obese group's SM, SB, and the safe margin were $1.8 \pm 0.3,2.7 \pm 0.5$, and 2.1 to 2.2 $\mathrm{cm}$, respectively.

Conclusion This study will help us to set the standard depth of safe needle insertion into the rhomboid major muscle in an effective manner without causing any complications.
\end{abstract}

Keywords Pneumothorax, Trigger point injection, Rhomboid major muscle

\section{INTRODUCTION}

Myofascial pain syndrome is a painful musculoskeletal condition produced by myofascial trigger points [1].

Received May 24, 2013; Accepted September 17, 2013

Corresponding author: Seong Ho Jang

Department of Rehabilitation Medicine, Hanyang University Guri Hospital, Hanyang University College of Medicine, 153 Gyeongchun-ro, Guri 471-701, Korea

Tel: +82-31-560-2380, Fax: +82-31-564-4654, E-mail: systole77@hanmail.net

(c) This is an open-access article distributed under the terms of the Creative Commons Attribution Non-Commercial License (http://creativecommons. org/licenses/by-nc/3.0) which permits unrestricted noncommercial use, distribution, and reproduction in any medium, provided the original work is properly cited.

Copyright $\odot 2014$ by Korean Academy of Rehabilitation Medicine
Trigger point injection is one of the treatment methods for this condition and is known to provide temporary or long-term relief [2]. When a skilled operator performs an injection, the procedure is generally very safe, but some side effects have been reported [3]. The reported side effects include pain, nerve injury, bleeding, infection, and some serious complications, such as pneumothorax [4,5]. Iatrogenic pneumothorax can occur when patients are treated with trigger point injection on their shoulder and neck region, such as the trapezius muscle, rhomboid major or minor muscles. Among these muscles, the rhomboid major muscle is very thin, and the thicknesses of the skin, subcutaneous fat layer and other soft tissues around the muscle vary between individuals. Furthermore, in 
the deep part of the muscles, there are intercostal nerves, blood vessels, and pleura. Thus, the determination of an appropriate injection depth becomes one of the most important factors when performing injections into these muscles. However, there is no research with clear criteria regarding the depth of needle insertion that allows safe and effective alleviation of pain. With this in mind, we carried out this study to provide some reference for safe and effective treatment through determining an appropriate injection depth according to the body type of patients using body mass index (BMI) during trigger point injection into the rhomboid major muscle.

\section{MATERIALS AND METHODS}

\section{Subjects}

Our subjects were 62 outpatients and hospitalized patients who had visited the rehabilitation medicine department of our hospital for pain in their upper back or shoulder. Patients with a history of fractures or surgery around the shoulder were excluded from the study because of the potential of anatomical changes around their shoulders. Also, patients who could not maintain their posture for more than 5 minutes because of serious

Table 1. General characteristics of subjects

\begin{tabular}{lccc}
\hline & $\begin{array}{c}\text { Total } \\
(\mathbf{n = 6 2})\end{array}$ & $\begin{array}{c}\text { Male } \\
(\mathbf{n = 1 9 )}\end{array}$ & $\begin{array}{c}\text { Female } \\
(\mathbf{n = 4 3})\end{array}$ \\
\hline Age $(\mathrm{yr})$ & $53.6 \pm 13.2$ & $47.1 \pm 18.0$ & $56.6 \pm 10.7$ \\
Height $(\mathrm{cm})$ & $160.4 \pm 9.0$ & $170.9 \pm 7.1$ & $155.7 \pm 5.1$ \\
Weight $(\mathrm{kg})$ & $60.8 \pm 9.2$ & $66.5 \pm 10.5$ & $58.3 \pm 7.4$ \\
\hline BMI $\left(\mathrm{kg} / \mathrm{m}^{2}\right)$ & $23.6 \pm 3.0$ & $22.7 \pm 2.4$ & $24.1 \pm 3.2$ \\
\hline
\end{tabular}

Values are presented as mean \pm standard deviation. BMI, body mass index. pain or limited range of motion were excluded. Age, sex, weight, and BMI of the patients are described in Table 1.

\section{Measurements}

We measured the depth and thickness of the rhomboid major muscle by ultrasonography. During the study, patients put their hand of the affected side on the opposite shoulder to relax the rhomboid major muscle (Fig. 1). A transducer was then placed at point $1 \mathrm{~cm}$ medial to the midpoint of the medial border of the scapula of the affected side, parallel to the medial border, and perpendicular to the skin surface (Fig. 2). Great care was taken not to exert excessive pressure with the transducer. Participants were required to inspire fully and hold their breath during measurement. Following this, two values were measured; the distance from the skin to the surface of the rhomboid major muscle was named SM (skin-muscle distance), indicating the minimal depth for the needle tip needle during trigger point injection into the rhomboid major muscle. The distance between the skin and the surface of the rib was named SB (skin-bone distance) (Fig. 3). The

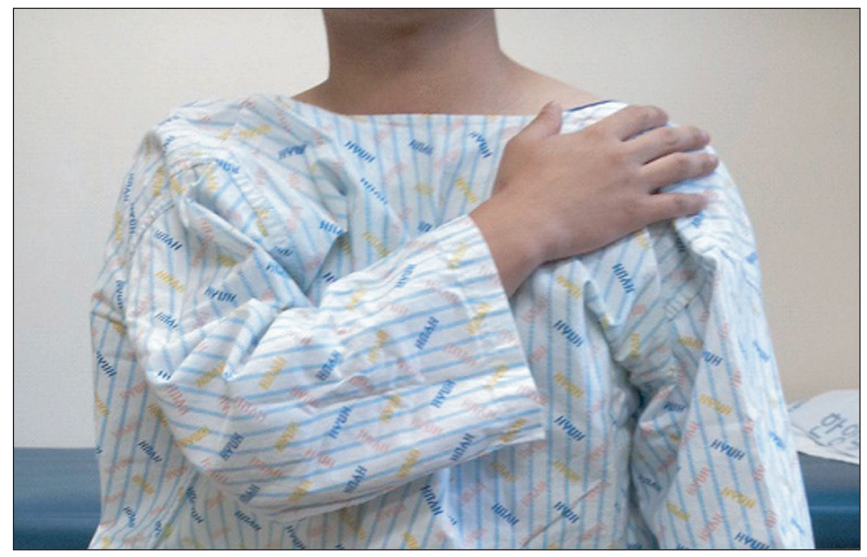

Fig. 1. Patient's posture during measurement.
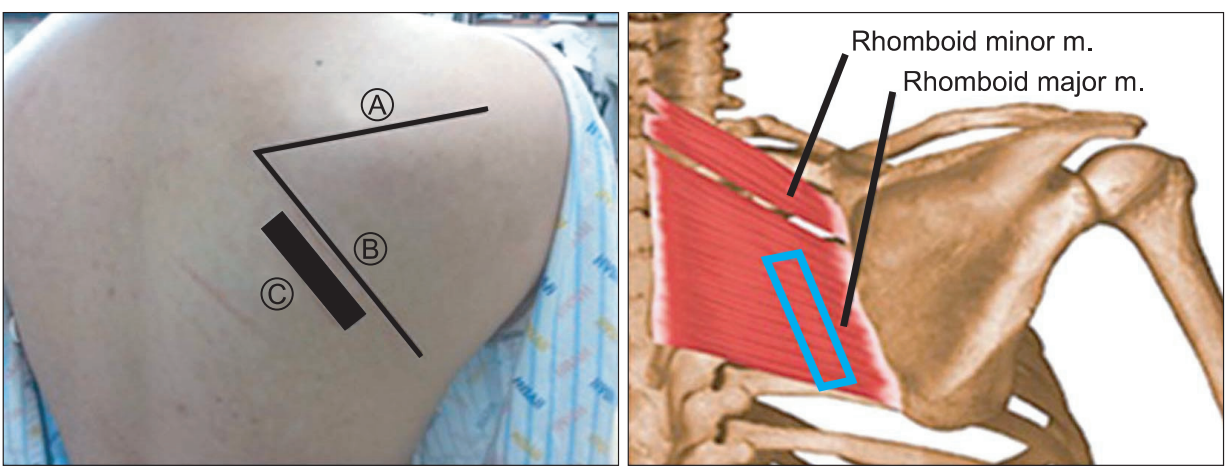

Fig. 2. Placement of probe during measurement: $\mathrm{A}$, the spine of scapula; B, the medial border of scapula; and $\mathrm{C}$, location of probe. 
SB indicated the maximum depth of the needle tip that can be inserted safely with no danger of pneumothorax or injury of to intercostal nerves and vessels. The difference between SB and SM was the thickness of the rhomboid major muscle. When the tip of the needle was in this range, it indicated that the needle tip was safely located within the rhomboid major muscle. We also defined a range between mean +1 SD of SM and the mean-1 SD of $\mathrm{SB}$ as a safe margin of needle depth in each group.

This study was carried out by a skillful medical specialist of rehabilitation medicine, using Accuvix V10 (Medison, Seoul, Korea) and linear probes with a frequency between 5 and $13 \mathrm{MHz}$. The subjects were divided into 3 groups according to BMI: 1) BMI less than $23 \mathrm{~kg} / \mathrm{m}^{2}$ (underweight or normal group); 2) $23 \mathrm{~kg} / \mathrm{m}^{2}$ or more to less than $25 \mathrm{~kg} / \mathrm{m}^{2}$ (overweight group); and 3) $25 \mathrm{~kg} / \mathrm{m}^{2}$ or

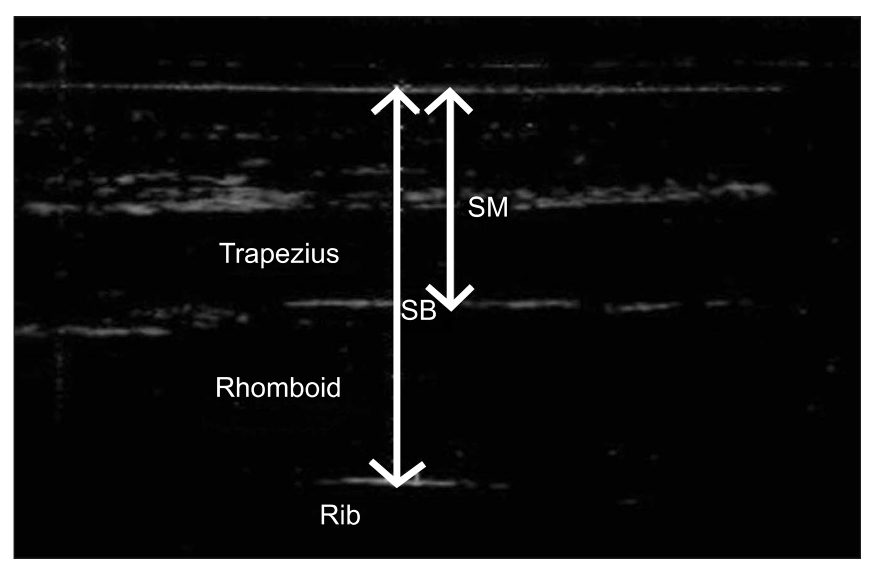

Fig. 3. Transverse view of ultrasonographic image of the rhomboid major muscle at a point $1 \mathrm{~cm}$ medial to the midpoint of the medial border of the scapula. SM, distance from the skin to the rhomboid major muscle; SB, the distance from the skin to the rib. more (obese group).

\section{Statistical analysis}

SPSS ver. 18.0 (SPSS Inc., Chicago, IL, USA) was used for statistical analysis. The independent t-test was used to compare the measured values between males and females. Statistical difference of the measured values between the groups according to the BMI was analyzed using the one-way analysis of variance (ANOVA) test.

\section{RESULTS}

The study population consisted of 19 men and 43 women with an age range of $53.6 \pm 13.2$ years (from 23 to 78 ). In terms of BMI, there was no statistical difference between men and women $(\mathrm{p}=0.09)$. The baseline characteristics of the subjects are provided in Table 1. SM, SB, and the difference between SM and SB did not differ significantly by gender (Table 2).

The number of subjects in each group divided by the BMI was 29 for the underweight or normal weight group, 14 in the overweight group, and 19 in the obese group (Table 3). Both SM and SB were deeper in the group with higher BMI $(\mathrm{p}<0.001)$ although the difference between

Table 2. Distances from the skin to the rhomboid major muscle (SM), skin to the rib (SB), and the thickness of rhomboid major muscle (the difference between SM and $\mathrm{SB}$ ) in each group according to gender

\begin{tabular}{lccc}
\hline & Male & Female & p-value \\
\hline SM $(\mathrm{cm})$ & $1.4 \pm 0.4$ & $1.5 \pm 0.3$ & 0.60 \\
SB $(\mathrm{cm})$ & $2.4 \pm 0.5$ & $2.3 \pm 0.5$ & 0.83 \\
SB-SM $(\mathrm{cm})$ & $1.0 \pm 0.4$ & $0.9 \pm 0.2$ & 0.31 \\
\hline
\end{tabular}

Values are presented as mean \pm standard deviation.

Table 3. Distances from the skin to the rhomboid major muscle (SM), skin to the rib (SB), the thickness of rhomboid major muscle (the difference between SM and SB), and the safe margin of needle depth in each group according to BMI

\begin{tabular}{|c|c|c|c|c|}
\hline & $\begin{array}{l}\text { Underweight or normal }^{\text {a) }} \\
\qquad(\mathrm{n}=29)\end{array}$ & $\begin{array}{l}\text { Overweight }^{b)} \\
(n=14)\end{array}$ & $\begin{array}{l}\text { Obese }^{c)} \\
(n=19)\end{array}$ & p-value \\
\hline $\mathrm{SM}(\mathrm{cm})$ & $1.2 \pm 0.2$ & $1.4 \pm 0.2$ & $1.8 \pm 0.3$ & $<0.001$ \\
\hline $\mathrm{SB}(\mathrm{cm})$ & $2.1 \pm 0.4$ & $2.4 \pm 0.9$ & $2.7 \pm 0.5$ & $<0.001$ \\
\hline $\mathrm{SB}-\mathrm{SM}(\mathrm{cm})$ & $0.9 \pm 0.3$ & $1.0 \pm 0.2$ & $0.8 \pm 0.3$ & 0.24 \\
\hline Safe margin of needle depth ${ }^{\mathrm{d})}(\mathrm{cm})$ & $1.4-1.7$ & NA & $2.1-2.2$ & - \\
\hline
\end{tabular}

Values are presented as mean \pm standard deviation.

BMI, body mass index; NA, not available.

${ }^{\mathrm{a})} \mathrm{BMI}<23,{ }^{\mathrm{b})} 23 \leq \mathrm{BMI}<25,{ }^{\mathrm{c})} \mathrm{BMI} \geq 25$, and ${ }^{\mathrm{d})}$ defined as a range between mean+1 SD of SM and mean-1 SD of SB. 
the underweight or normal group and the overweight group were not statistically significant ( $\mathrm{p}=0.07$ for $\mathrm{SM}$, $\mathrm{p}=0.19$ for SB). The thickness of the rhomboid major muscle (the difference between SM and SB) was not significantly difference between the groups divided by BMI. The safe margin was 1.4 to $1.7 \mathrm{~cm}$ in the underweight or normal group and 2.1 to $2.2 \mathrm{~cm}$ in the obese group. In the overweight group, the safe margin of needle depth could not be calculated because SB-1 SD was larger than SM+1 SD in this group (Table 3 ).

\section{DISCUSSION}

The purpose of this study was to provide the standard depth of needle insertion during trigger point injection into the rhomboid major muscle. According to our results, the depth of needle insertion was dependent on the patient's BMI, but gender did not influence SM and SB in our study. However, the number of male participants was small, thus there should be an additional study to compare the values between men and women. Although both SM and SB were deeper in the group with higher BMI, the difference between SM and SB (the thickness of rhomboid major muscle) was not significantly different between the groups divided by BMI. This suggests that the main factor influencing the depth of insertion is the thickness of fat tissue, not muscle. In addition, we set a range between the mean +1 SD of SM and mean-1 SD of $\mathrm{SB}$ as a safe margin of needle depth in each group divided by BMI. This was done to assure that the needle tip is placed safely in the rhomboid major muscle without any possibility of pneumothorax, which was achieved in $71 \%$ of all patients. However, even if the needle tip is inserted deeper than SB, pneumothorax does not occur until the needle tip reaches the pleura. According to Mohr et al. [6], the average width of the rib around the rhomboid major muscle is $7.5 \pm 1.8 \mathrm{~mm}$, and this value is the difference between the depth to the rib and to the pleura. Therefore, safety is guaranteed in much more than $71 \%$ of patients because of this width of the rib.

To our knowledge, this is the first trial that uses ultrasonography to set the standard depth of safe needle insertion according to the patient's body type during trigger point injection. According to Dupont et al. [7], it is widely acknowledged that real-time ultrasonography is accurate in precisely measuring muscle thickness, and for being time-efficient. Ultrasonography has also been reported to be as accurate as magnetic resonance imaging when measuring the cross-sectional area of low back muscles [8]. Also, there have been some previous studies using ultrasonography to measure the depth or cross-sectional area of a muscle. For example, Yang et al. [5] used ultrasonography to measure the thickness of the interscapular soft-tissue. However, they did not divide their participants into subgroups by the BMI. They also enrolled normal young adults, but the present study was conducted with elderly patients with shoulder pain.

On the other hand, there is a controversy about the appropriate depth of needle insertion during trigger point injection. Ceccherelli et al. [9] revealed that when injecting into a trigger point in the low back muscle, there were no significant differences regarding their shortterm pain relief between the superficially inserted group and deeply inserted group. Another study compared the effects on 35 older adults with chronic low back pain by injecting into a trigger point with $3-\mathrm{mm}$ depth and $2-\mathrm{cm}$ depth [10]. The study revealed that the group with deep insertion showed greater effects of pain relief as well as improvement in quality of life, although the results were not statistically significant.

In contrast, Baldry [11] reported that more deeply inserted needles cause more pain than superficially inserted needles. Kalichman and Vulfsons [12] also suggested superficial injection.

The best outcome wtihout complications may be expected by injecting a needle precisely into the exact location of the trigger point.

There are a few limitations to consider in our study. Although we calculated the standard depth of insertion in each group, there may be some variations because the depth from the skin to the rhomboid major muscle or its thickness may be different according to the patient's posture. Also, even if we measured the vertical distance from the skin to the rhomboid major muscle or rib, the needle is not always inserted into the skin vertically in clinical practice, so there may be some errors in applying the values we measured in all situations. Moreover, even if we specify a certain point as the standard location in order to maintain consistency of measurement, for a real patient, the trigger point may exist at another place.

However, at present, since the criteria of needle depth at the trigger point injection of the rhomboid major mus- 
cle have not been elucidated, we expect that the values measured by this study would be useful reference values ensuring safer and more effective practice by physicians.

Even though the total number of subjects of this study may be too small to give statistical meaning, if we conduct further research with a larger number of subjects in the future, we would be able to formulate more accurate standard values.

In conclusion, we measured the values that can help us predict an appropriate depth of needle insertion during a trigger point injection. If we inject a needle at the trigger point of the rhomboid major muscle with these values in mind, we are more likely to deliver a safer and more efficient procedure.

\section{CONFLICT OF INTEREST}

No potential conflict of interest relevant to this article was reported.

\section{ACKNOWLEDGMENTS}

This study was supported by a grant of the Korean Health Technology R\&D Project, Ministry of Health \& Welfare, Korea (A112074).

\section{REFERENCES}

1. Moon CW. Myofascial pain syndrome. Korean J Pain Soc 2004;17(Suppl):S36-S44.

2. Scott NA, Guo B, Barton PM, Gerwin RD. Trigger point injections for chronic non-malignant musculoskeletal pain: a systematic review. Pain Med 2009;10:54-69.

3. Melzack R, Stillwell DM, Fox EJ. Trigger points and acupuncture points for pain: correlations and impli- cations. Pain 1977;3:3-23.

4. Fitzgibbon DR, Posner KL, Domino KB, Caplan RA, Lee LA, Cheney FW. Chronic pain management: American Society of Anesthesiologists Closed Claims Project. Anesthesiology 2004;100:98-105.

5. Yang CS, Chen HC, Liang CC, Yu TY, Hung D, Tseng TC, et al. Sonographic measurements of the thickness of the soft tissues of the interscapular region in a population of normal young adults. J Clin Ultrasound 2011;39:78-82.

6. Mohr M, Abrams E, Engel C, Long WB, Bottlang M. Geometry of human ribs pertinent to orthopedic chest-wall reconstruction. J Biomech 2007;40:1310-7.

7. Dupont AC, Sauerbrei EE, Fenton PV, Shragge PC, Loeb GE, Richmond FJ. Real-time sonography to estimate muscle thickness: comparison with MRI and CT. J Clin Ultrasound 2001;29:230-6.

8. Watanabe K, Miyamoto K, Masuda T, Shimizu K. Use of ultrasonography to evaluate thickness of the erector spinae muscle in maximum flexion and extension of the lumbar spine. Spine (Phila Pa 1976) 2004;29:14727.

9. Ceccherelli F, Rigoni MT, Gagliardi G, Ruzzante L. Comparison of superficial and deep acupuncture in the treatment of lumbar myofascial pain: a doubleblind randomized controlled study. Clin J Pain 2002;18:149-53.

10. Itoh K, Katsumi Y, Kitakoji H. Trigger point acupuncture treatment of chronic low back pain in elderly patients: a blinded RCT. Acupunct Med 2004;22:170-7.

11. Baldry P. Superficial versus deep dry needling. Acupunct Med 2002;20:78-81.

12. Kalichman L, Vulfsons S. Dry needling in the management of musculoskeletal pain. J Am Board Fam Med 2010;23:640-6. 